results may be seen as justification for setting up a large multicentre trial to obtain results rapidly-there were 37 institutions taking part.

In breast cancer with two to three affected nodes the overall prognosis is sufficiently bad to warrant exposing potentially cured patients to the hazards of long-term chemotherapy. These risks have not yet been clearly defined, but induction of neoplasms (especially in the lymphoid tissues) is a possibility that must be borne in mind. Breast cancer looks a promising tumour for this type of study: favourable results can be obtained with chemotherapy in some patients with advanced disease, and it can be staged reasonably accurately. The lessons gained from the lymphomas are the guide lines in this disease. In other tumours, such as colonic cancer, perhaps more selective methods are needed to find the high-risk patients, and estimating postoperative carcinoembryonic antigen levels might be helpful. ${ }^{6} 7$ Such an argument could probably be extended to other cancers as the development of tumour markers improve, ${ }^{8}$ so that subclinical residual tumour can be identified after surgery. These cases would then fulfil the criterion of having a minimal cancer mass, and clearly should be considered separately from those with widespread residual disease as may be left behind in gastrointestinal or ovarian cancer.

Once the patient is committed to an adjuvant regimen intermittent chemotherapy may need to be continued for one, two, or more years; and on the face of it this makes mephalan particularly attractive, as it is relatively free of troublesome side effects. Maybe in a year or two we will know if it helps in any other common solid tumours.

1 The Times, 8 March 1975, p. 3.

2 Zubrod, C. G., Life Sciences, 1974, 14, 809.

Union International Contre Cancer, Technical Report Series, Vol. 14 Controlled Therapeutic Trials in Cancer. Geneva, U.I.C.C., 1974.

4 Moertel, C., in Cancer Medicine, ed. J. Holland and E. Frei. Philadelphia Lea and Febiger, 1973.

5 Fisher, B., et al., New England fournal of Medicine, 1975, 292, 117.

- Booth, S. N., et al., British Medical fournal, 1974, 4, 183.

7 MacKay, A. M., et al., British Medical fournal, 1974, 4, 382

8 Munro-Neville, A., fournal of Clinical Pathology, 1974, 27, suppl. 17, 119.

\section{Perinatal Research}

Perinatal research needs no justification from us, for without it what progress would there be in our efforts to improve the outlook for future generations? Yet because advances in this field are so rapid there is a need to pause from time to time and take stock of the direction in which perinatal research is going.

It was Barcroft in Cambridge who, by his researches on the fetus, indirectly questioned whether obstetric care was concentrated on the mother to such an extent that the main purpose of pregnancy was sometimes forgotten. He was much concerned with environmental influences on fetal development, recognizing that until normal development was understood it would not be possible to investigate the abnormalities that lead to defects and even death. Almost all his observations were, by necessity, made on animals, for at the time he was working studies on the human fetus were unthinkable. His example has influenced many who have continued his work, notably in Britain at the Nuffield Institute for Medical Research under the direction of G. S. Dawes. In addition to the accumulation of knowledge about intrauterine life one of the results of these efforts has been to stimulate clinicians to improve their care of the fetus and newborn. The last 15 years has seen a surge of activity among obstetricians and paediatricians that has led to the creation of perinatal medicine as a subject spanning fetal and early neonatal life. Concurrently there has been an improvement in clinical practice, so that no longer is the view acceptable that perinatal mortality has reached an irreducible minimum. The condition of the baby, rather than life or death, is becoming the yardstick of clinical success. This change in attitude is just one of the contributions that stem from Barcroft's early researches.

This year has seen the publication of the third in the series of the British Medical Bulletin ${ }^{1}$ devoted to fetal and neonatal research. The issue upholds the high standard of science and scholarship of its predecessors. ${ }^{2}$ In particular, the articles on fetal lung maturation, fetal breathing, and low-birth-weight infants illustrate the contribution that physiology has made to perinatal medicine. However, throughout the issue there is a certain imbalance in favour of physiological as compared with clinical perinatal research-inevitably the product of most of the authors being physiologists. It is disappointing to find in a publication devoted to medicine that some of the recent advances which have made a major impact on fetal care, such as detection of congenital defects, intrauterine therapy, and the early diagnosis of fetal asphyxia, receive no mention. Perhaps omissions were not so noticeable in the previous issues because at the time of publication obstetrics was more of an art than the science it is now becoming. Whatever the cause it is certain that while physiologists have firmly established an important role for themselves in perinatal research questions in need of urgent answers are arising as a result of modern obstetric and paediatric clinical practice. One example is seen in the clinical condition of failure of the fetus to grow in the latter weeks of pregnancy. Growth retardation is regarded as evidence that placental function is failing and often as an indication that the baby needs to be delivered before full maturity. Such a solution is far from ideal; it would be preferable to prevent the condition at an earlier stage in pregnancy or alternatively to provide nutritional support to the fetus and so avoid the need for premature delivery. Before any advance of this kind can be made a more detailed knowledge of the factors responsible for fetal growth is required, much of which can be obtained only in the laboratory with the help of basic scientists.

The concept of the basic scientist working in close collaboration with the clinician is not new. The Wellcome Trust has funds available for this purpose, and, more specifically in the field of perinatal medicine, the departments of Obstetrics and Gynaecology and of Paediatrics at the John Radcliffe Hospital are adjacent to the Nuffield Institute. Young clinicians who enter an academic career in medicine by spending up to three years in a basic science department are recognizing the need for a sound training in research methods. Where the difficulty lies in putting this co-operative approach into practice, so that it is of benefit to the patient, is the difference in outlook between clinicians and laboratory-orientated workers. The clinician sometimes finds the need for research hard to understand, while the laboratory worker, proud of his achievements, may feel threatened that his efforts will be submerged by the glamour of clinical medicine. Fortunately barriers such as these are increasingly being broken down as each group recognizes its dependence on the other.

Perinatal research has entered a new and exciting era. The clinical researcher is always at a disadvantage in studying experimentally the processes of pregnancy and the neonatal period because of the ethical objection to research that is not of obvious immediate benefit to the patient. Valid observations 
from the human fetus and neonate are almost impossible to obtain when pregnancy is uncomplicated, though it is surprising what has been achieved despite these restrictions. Clinical abnormalities can be investigated more easily, but again ethical considerations limit the experimental approach.

For these reasons itseems likely that we shallsee physiologists increasingly turning their minds to animal models which mimic pathological conditions that affect the fetus and neonate. Examples of such models are the streptozotocin-treated monkey that develops diabetes ${ }^{4}$ and the sheep with experimental reduced uterine blood flow which results in fetal growth retardation. ${ }^{5}$ Developments of this kind should prove of immense value in safeguarding the life of the fetus-and hence in improving the health of future generations.

1 Perinatal Research, British Medical Bulletin, 1975, 31, No. 1.

2 Fetal and Neonatal Physiology, British Medical Bulletin, 1961, 17, No. 2. 3 The Fetus and the Newborn: Recent Research, British Medical Bulletin, 1966, 22, No. 1 .

4 Reynolds, A., et al., Diabetes, 1974, 23, 777.

5 Creasy, R. K., et al., in Foetal and Neonatal Physiology, ed. K. E. Comline, et al., p. 398. London, C.U.P., 1973.

\section{Sunscreens}

Dermatologists soon become aware of the deleterious effects of the sun's rays on the skin, but unfortunately their cautious respect for sunlight is not shared by the rest of the population. The immediate sensation of warmth given by the sun's infrared emission, the delayed suntan with its boost to morale (mostly determined by fashion), and the insensible production of vitamin $\mathrm{D}$ are clearly beneficial, but in the susceptible the harm far outweighs the benefit. Solar damage to the skin used to be confined to those who worked in the open, but in the last 50 years sun-worship on a large scale has produced an epidemic of serious proportions. In those parts of the world where the sun's rays are intense and reliable and the inhabitants are not heavily pigmented, such as Australia and the United States, skin cancers can affect up to $30 \%$ of patients attending dermatological clinics.

Ultraviolet rays are the most harmful, producing basal and squamous cell carcinomata, melanomata, and solar keratosesand in addition all the changes associated with ageing: atrophy, wrinkling, lentigines, telangiectasia, and elastosis. Among skin disorders provoked by visible light are porphyria, lightsensitive dermatitis, phototoxic drug eruptions (due to chlorpromazine, sulphonamides-antidiabetic, antibiotic, and diuretic-demethylchlortetracycline, nalidixic acid, and many others), lupus erythematosus, polymorphous light eruption, and solar urticaria.

Melanin in the epidermis is the most effective sunscreen that man possesses, but its density is determined by genetic factors at present beyond our control. Adequate clothing will protect those parts that can be covered, but topical preparations and oral medication may be needed to protect exposed areas. As a result of the rise in serious solar reactions the search for efficient sunscreens has been intensified, and recently the relative efficacy of safe agents has been assessed. ${ }^{1-5}$

Only opaque screens such as titanium dioxide and zinc oxide will protect against visible light, but few formulae are commercially available that are cosmetically acceptable. ${ }^{6}$ Among satisfactory ultraviolet light screens are derivatives of aminobenzoic acid, cinnamates and benzophenones, but some give better protection from shortwave ultraviolet light, which causes sunburn, and others from longwave ultraviolet light, which may aggravate porphyria and cause photodermatitis. Their efficacy depends on the frequency of application, the thickness of the film applied, the vehicle used in the formulation, and whether it is washed off by bathing. Most authorities agree that $5 \%$ para-aminobenzoic acid in $70 \%$ ethyl alcohol gives the best protection, but it is by no means foolproof. In those with toxic reactions to sunlight such as photodermatitis or polymorphous light eruption chloroquine and systemic corticosteroid therapy may prevent or lessen the reaction, but the risks of these drugs must be balanced against the inconvenience of the disorder.

Individuals who cannot produce adequate melanin on sun exposure burn readily in the sun, and are therefore likely to take precautions, but they may not realize that the low dose of ultraviolet radiation reflected from cloudy skies will produce the same ravages of their skin as a high dose, though the effect will take longer to develop. Clearly the susceptible-albinos and redheaded Celts run the greatest risk-should avoid the sun, apply frequent effective ultraviolet light filters on exposed areas, and seek indoor employment; they should be advised of the dangers of the sun when they are children so that a cautious approach to the sun becomes a lifelong habit. For those who still wish to defy the sun, there are many safe proprietary products and cosmetics that contain ultraviolet light filters, ${ }^{7}$ but they do not provide complete protection. Provided this is recognized then the serious consequences of solar damage may become less frequent in subsequent generations.

\footnotetext{
1 Pathak, M. A., Fitzpatrick, T. B., and Frenk, E., New England fournal of Medicine, 1969, 280, 1459.

2 Katz, S. I., Archives of Dermatology, 1970, 101, 466.

3 Findlay, G. H., and Nel, S. J., British fournal of Dermatology, 1971, 85, suppl. 7, 44. 4 MacLeod, T. M., and Frain-Bell, W., British fournal of Dermatology, 1971,

5 Kahn, G., and Curry, M. C., Archives of Dermatology, 1974, 109, 510.

6 MacLeod, T. M., and Frain-Bell, W., British fournal of Dermatology, $1975,92,149$.

7 Groves, G. A., and Robertson, D. F., Medical fournal of Australia, 1974, $2,898$.
}

\section{Eradication of Smallpox}

Whether or not smallpox is ever finally eradicated there is no doubt of the great reduction in its incidence which has occurred over the past eight years. In 1962 freeze-dried vaccine became available, and this was of great value when the eradication campaign was started by the World Health Organization in 1967. At the end of that year smallpox was notified by 38 countries in respect of 105000 cases-perhaps $5-10 \%$ of the real figure. Vaccination of the whole population is not necessary for eradication and the strategy has been "search and containment," followed by appraisal and surveillance. In the succeeding years countries reporting smallpox numbered 37, 25, 22, 9, 9, and 5; and only India, Pakistan, Bangladesh, and Ethiopia in 1974. The search for cases may give the impression of higher incidence; thus in 1974 there were 211000 cases reported, but this figure reflects the gross under-reporting of previous years.

The current prospects for the success of such a campaign were reviewed at a recent symposium at the Royal Society of Tropical Medicine and Hygiene in London. Permanent eradication depends on there being no animal reservoir, and this seems likely to be the case. Monkeypox is a disease of 